\title{
STUDY OF POROSITY DISTRIBUTION IN SPIN CAST ZINC ALLOY CASTINGS
}

\author{
Martin BAJČIČÁK, Roland ŠUBA \\ SLOVAK UNIVERSITY OF TECHNOLOGY IN BRATISLAVA, \\ FACULTY OF MATERIALS SCIENCE AND TECHNOLOGY IN TRNAVA, \\ INSTITUTE OF PRODUCTION TECHNOLOGIES, \\ Ulica JÁna Bottu 2781/25, 91724 TRNAVA, SlovaK RePUbliC \\ e-mail: martin.bajcicak@stuba.sk,roland.suba@stuba.sk \\ Received: 31.05.2018, Accepted: 12.07.2018, Published: 19.09.2018
}

\begin{abstract}
Porosity distribution in the spin cast zinc alloy castings was observed. Results shows that it is influenced by rotations per minute and by the centrifugal and Coriolis' forces. The influence of Coriolis' force is higher at low rotation speed. Porosity in castings can be eliminated by high rotation speeds.
\end{abstract}

\section{Key words}

Porosity distribution, spin casting, zinc alloy

\section{INTRODUCTION}

Porosity in castings decreases mechanical and physical properties. The pores in the castings can be divided according to size into:

a) Micropores - (microsize gas bubbles) decreasing fatigue strength,

b) Macropores - (minimum size $0.5 \mathrm{~mm}$, centrally shrunk pores) decreasing structural strength (1).

Porosity can be classified as - gas porosity, shrinkage porosity and flow porosity (2).

Spin casting utilizes the centrifugal force for filling the silicone mould cavities with the liquid metal. Porosity of centrifugally cast castings is influenced by distance from the location of molten metal pouring. During the filling and solidification of molten metal, there is a radial movement of pores in the direction of the axis of rotation. The molten metal stream is influenced by Coriolis force (Fig. 1) (3). 


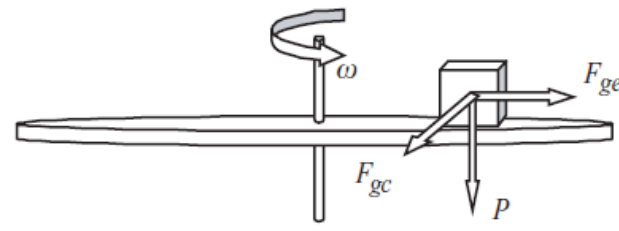

\section{$P$ - gravitation force $(N), F_{g c}$ - Coriolis force $(N), F_{g e}$ - centrifugal force $(N)$, $\Omega$ - angular rate (rad.s- 1 )}

Fig. 1 The scheme of forces in molten metal during centrifugal casting (3)

\section{EXPERIMENTAL}

The experimental samples were cast from $\mathrm{ZnA14Cu3}$ zinc alloy (Table 1) with pouring temperature of $430{ }^{\circ} \mathrm{C}$ on a centrifugal casting machine of Tekcaster series $100-\mathrm{D}$ with a casting cycle $20 \mathrm{~s}$ long and clamping pressure of $241.5 \mathrm{kPa}$. The mould rotates clockwise. The experimental samples were cast at 100, 200, 300, 400, 500 and $600 \mathrm{rpm}$.

The mould was made of a silicone rubber White CD - THT of $305 \mathrm{~mm}$ diameter. It was vulcanized at the pressure of $25 \mathrm{MPa}$ and temperature of $170{ }^{\circ} \mathrm{C}$ during 140 minutes. After its vulcanization, cooling and disassembly the vents and gating systems were cut with tools.

The die cavity and experimental samples are in the shape of cross to enable the use of four basic possibilities of gating (Fig. 2):

- direct,

- from right,

- from behind,

- from left.

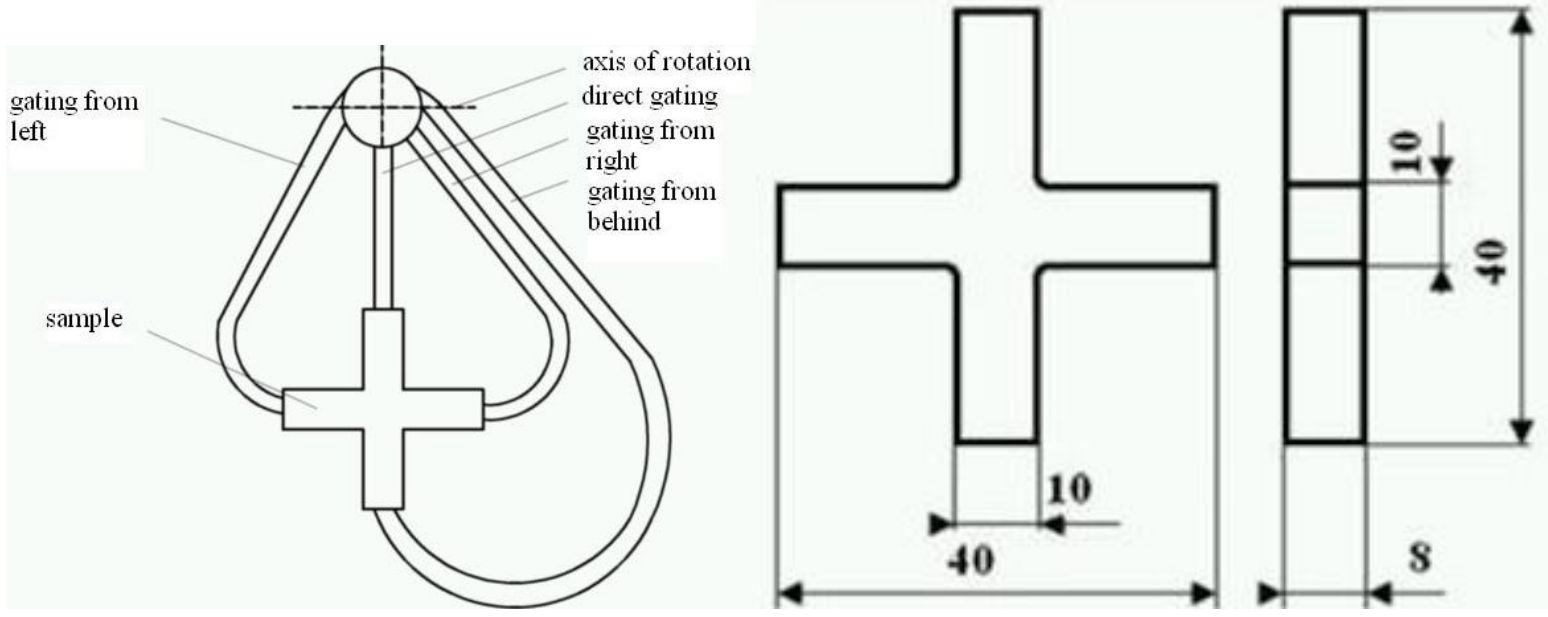

Fig. 2 The basic possibilities of gating at centrifugally cast castings and the dimensions of the test samples

\begin{tabular}{|c|c|c|c|c|c|c|c|c|c|c|}
\hline \multicolumn{1}{|c|}{ Table 1: The chemical composition of $\mathrm{ZnA} 14 \mathrm{Cu} 3$ alloy according to EN 1774 standard } \\
\hline Element & $\mathrm{Al}$ & $\mathrm{Cu}$ & $\mathrm{Mg}$ & $\mathrm{Pb}$ & $\mathrm{Cd}$ & $\mathrm{Sn}$ & $\mathrm{Fe}$ & $\mathrm{Ni}$ & $\mathrm{Si}$ & $\mathrm{Zn}$ \\
\hline Content & $3.8-$ & $2.7-$ & 0.0035 & max. & max. & max. & max. & max. & max. & residue \\
(wt. \%) & 4.2 & 3.3 & -0.06 & 0.003 & 0.003 & 0.001 & 0.020 & 0.001 & 0.020 & \\
\hline
\end{tabular}

The planar porosity of samples was determined on the five cross sections signed A to E (Fig. 3). 


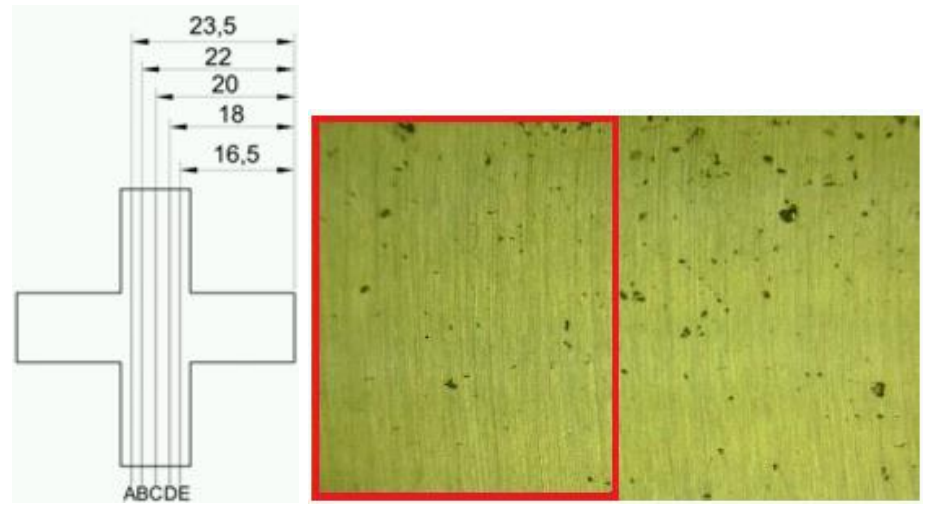

Fig. 3 The locations of test samples cross sections and the left side of observed area in red frame from the axis of mould rotation to the center of casting

\section{RESULTS}

The percentage of the planar porosity in various cross sections were evaluated by Image $\mathrm{J}$ software and the average results from three test samples can be seen in Figs. 4 - 7 as logarithmic curves.

Fig. 4 shows the results for direct gating, where higher percentage of porosity was at low mould rotations per minute. The porosity decreases for every cross sections with increasing mould rotations per minute. At $200 \mathrm{rpm}$, there is a large bubble, which influenced the results also in other cross sections. As can be seen, the samples with the minimum planar porosity were cast at $400-600 \mathrm{rpm}$ of the mould. At $600 \mathrm{rpm}$, there is zero porosity in all cross sections.

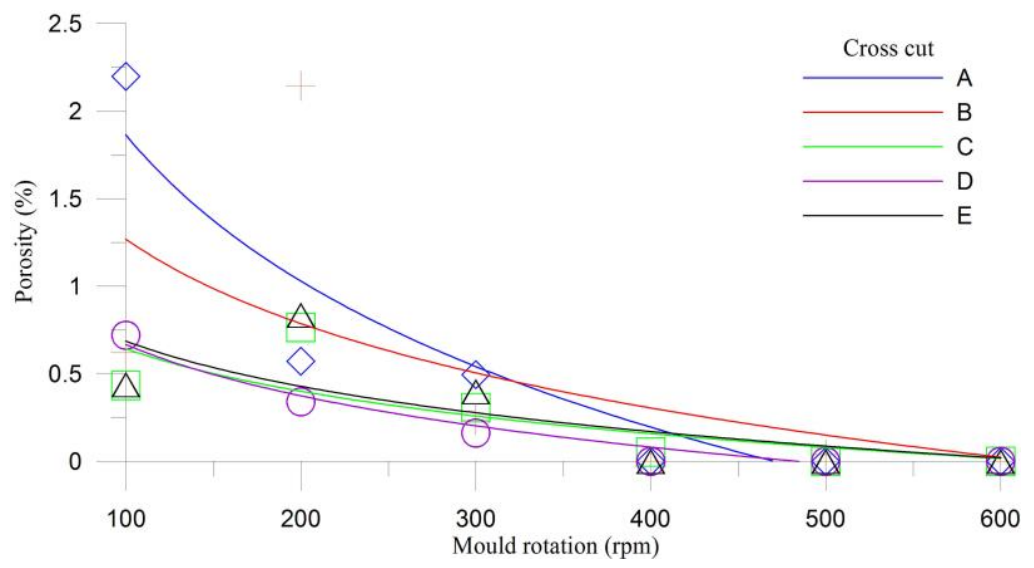

Fig. 4 The influence of mould rotations per minute on planar porosity at direct gating

Fig. 5 shows the results for gating from the right. At $100-300 \mathrm{rpm}$, the porosity is similar as at direct gating. In this case, porosity occurs also at higher mould rotations per minute. However, the porosity decreases with increasing the mould rotations per minute.

In Fig. 6 there are three samples with gating from behind the cast at higher mould rotations per minute. The samples cast at 100, 200 and $300 \mathrm{rpm}$ are misruns due to the low centrifugal force. Because of this, they cannot be evaluated. It can be said that this type of gating results in the minimum porosity. At $600 \mathrm{rpm}$, there is zero porosity in every cross sections.

Fig. 7 shows the results for gating from the left. In this case, the small centrifugal force at 100, 200 and $300 \mathrm{rpm}$ does not fill the mould cavity properly with molten metal. There is porosity only at $400 \mathrm{rpm}$. At higher number of rotations per minute, in this case $500 \mathrm{rpm}$ and $600 \mathrm{rpm}$, there are no porosity in the sample. 
The graphs below (Fig. 8 to 11) were drawn to compare the porosity percentage in the area less distant from the axis of the mould rotation (left side of test samples) and in the area more distant from the axis of the mould rotation (the right side of test samples).

At the cross sections A at $100 \mathrm{rpm}$ at direct gating and gating from the right, the porosities on the left hand side are below 50\%. This is caused by low centrifugal force at low mould rotations per minute. At higher mould rotations per minute, the higher centrifugal force causes more intensive movement of bubbles into the direction of the axis of rotation, and therefore the percentage of porosity on the left hand side is much higher. At 500 and $600 \mathrm{rpm}$, there is zero porosity.

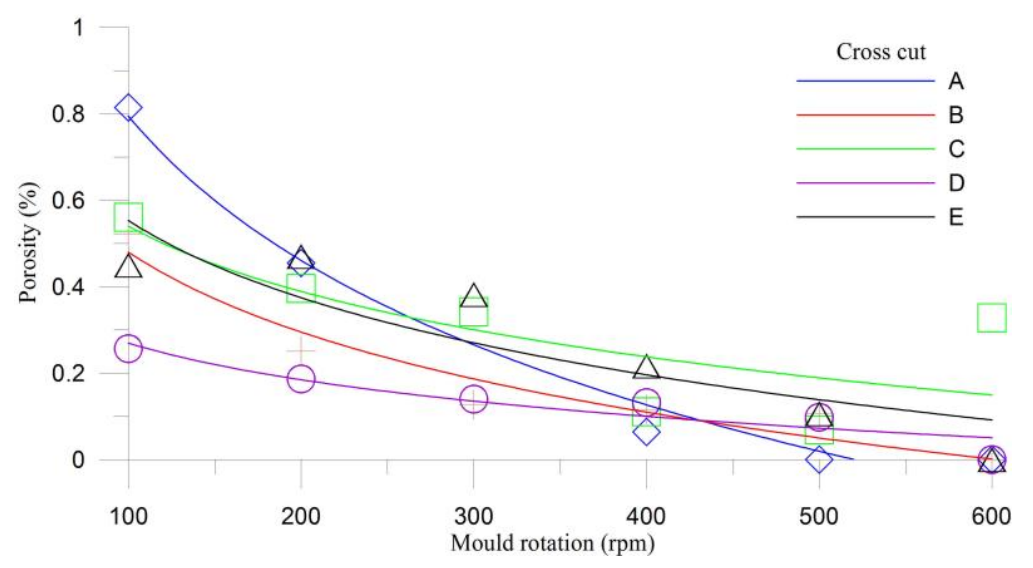

Fig. 5 The influence of mould rotations per minute on planar porosity at gating from the right

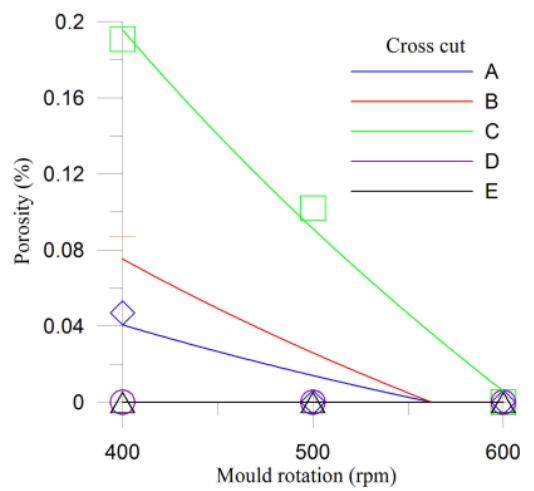

Fig. 6 The influence of mould rotations per minute on planar porosity at gating from behind

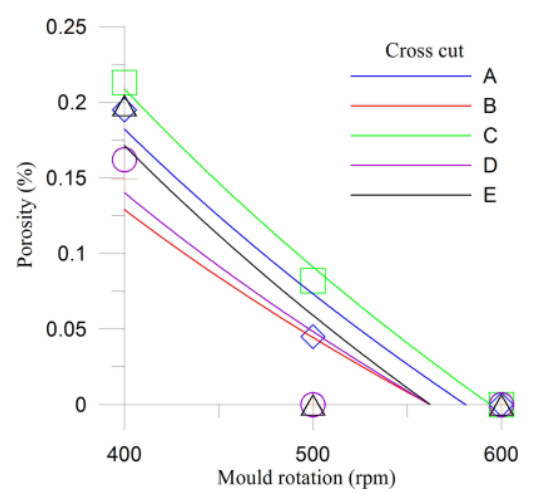

Fig. 7 The influence of mould rotations per minute on planar porosity at gating from the left

Similarly to the cross sections A, also cross sections B exhibited smaller percentage of the porosity at direct gating and gating from the right at $100 \mathrm{rpm}$. At the direct gating, the ratio of 
the porosity distribution - the left side to the right side reaches $16: 84$ due to low centrifugal force. At higher mould rotations per minute, at every type of gating the higher porosity is on the left hand side. At the direct gating at $400 \mathrm{rpm}$, the porosity is only on the left hand side of the observed area. At the gating from behind, there is no porosity.

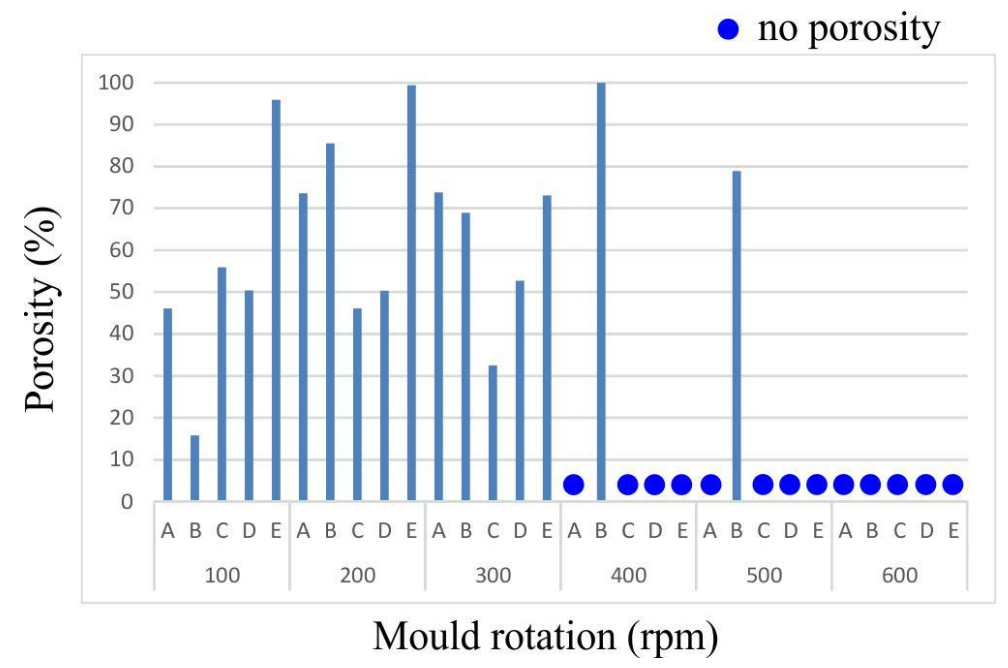

Fig. 8 The percentage of the porosity on the left side of the observed area-direct gating

At the cross sections $\mathrm{C}$, the pores are almost uniformly distributes on the left and right side, $\mathrm{i}$. e. $50: 50$ at lower mould rotations per minute at the direct gating and gating from the right. At the gating from the right at $600 \mathrm{rpm}$, the porosity is higher on the right side. This is deviation from other cross sections, where the higher percentages of porosity are on the left side of the observed area, closer to axis of rotation. The mould rotates clockwise and this influences the more uniform distribution of porosity in the observed area at the gating from the right.

When the mould cavity is filled from the right, the force from the flow acts against the Coriolis force. Because of this, the gas bubbles formed in the mould cavity will be distributed more uniformly than pores. At the gating from behind, there is zero porosity.

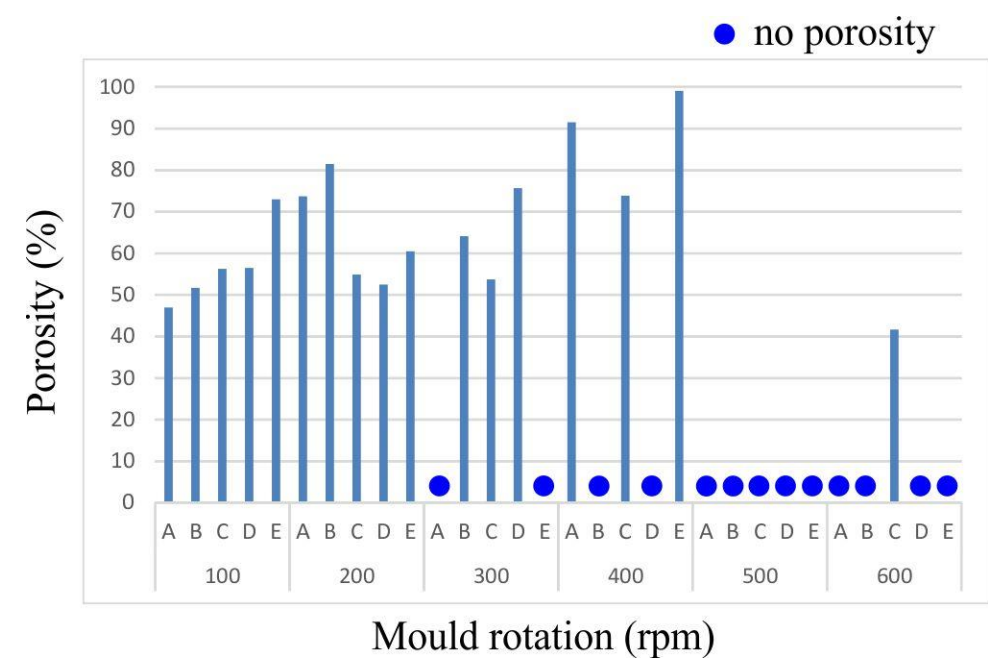

Fig. 9 The percentage of the porosity on the left side of the observed area-gating from the right

At the cross sections D, there are uniform distributions of pores at the direct gating at 100, 200 and $300 \mathrm{rpm}$, similarly to the cross sections C. Similar situation is at the gating from the right. At higher rotations per minute, there is zero porosity in most cases. Only at the gating from 
behind at $500 \mathrm{rpm}$, there are pores mainly on the left side of the observed area, and at the gating from the left at $400 \mathrm{rpm}$ where the pores are distributed as $60: 40$.

At the cross sections E, there is the lowest porosity. At the gating from the left and behind, there is zero porosity. The zero porosity is observed also at higher mould rotations per minute. At lower mould rotations per minute at the direct gating, the pores are mainly on the left side. At the gating from behind and from the left, there are small porosities with the most of pores on the left side of the observed area.

In every cross sections with porosity at $400 \mathrm{rpm}$, the porosity is mainly on the left side of the observed area. This can be explained by less turbulent filling.

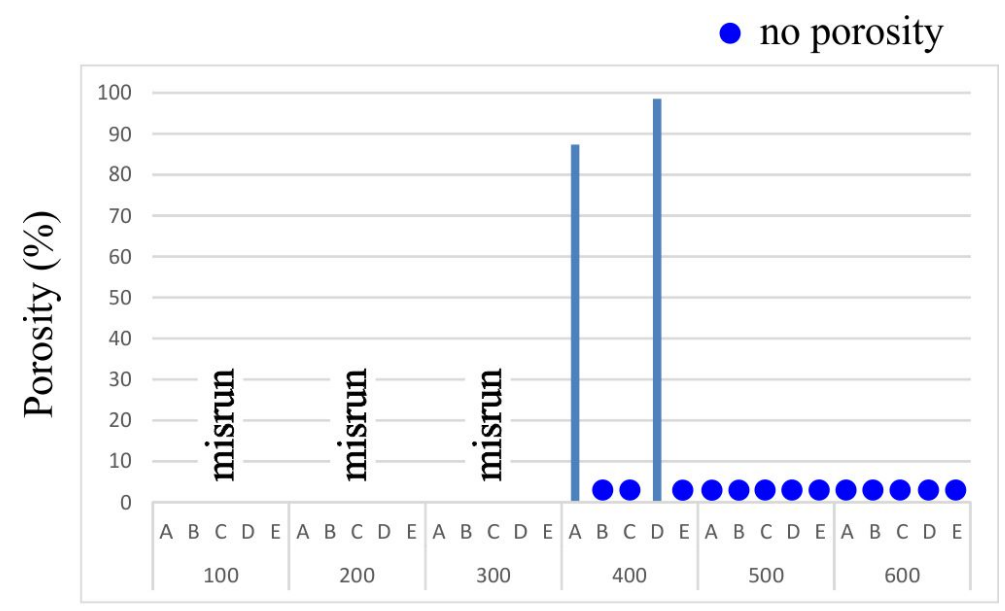

Mould rotation (rpm)

Fig. 10 The percentage of the porosity on the left side of the observed area-gating from behind

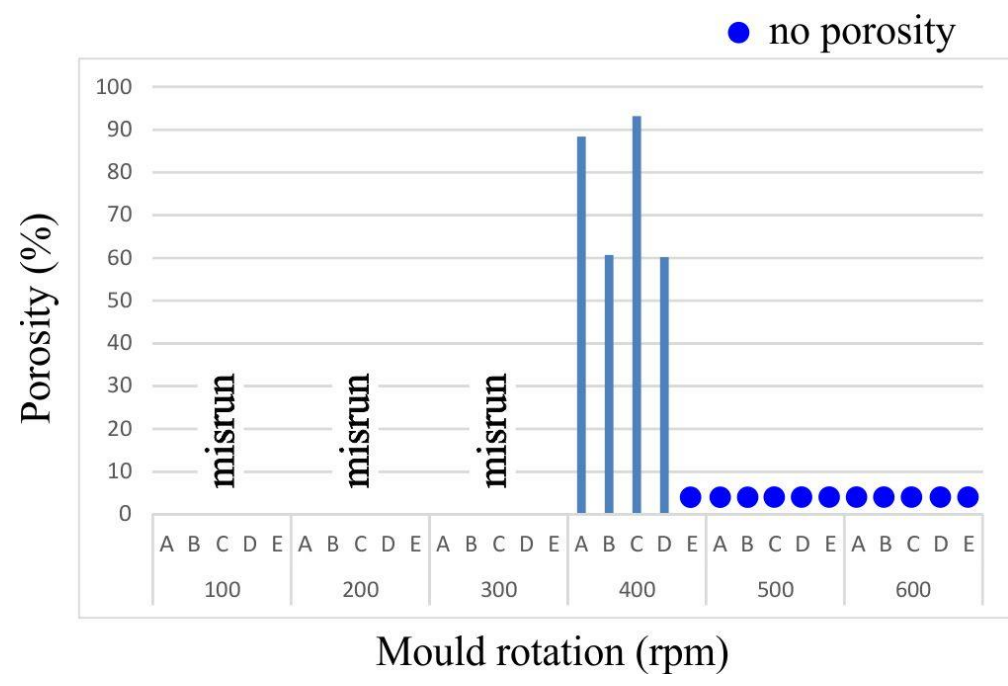

Fig. 11 The percentage of the porosity on the left side of the observed area-gating from the left

\section{DISCUSSION}

The porosity in the test samples was the gas one, the most common type of pores in castings. It is established in the samples with direct gating or gating from the right that the highest porosity is formed at the low mould rotations per minute (100, 200 and $300 \mathrm{rpm})$. Increase of the mould rotations per minute decreases porosity. The formed gas bubbles remain in the casting as pores due to the low centrifugal force. The formed bubbles can be small and 
large. The large bubbles cause irregularities during porosity evaluations in various cross sections. At the high mould rotations per minute, the minimum porosity is formed due to the higher centrifugal force on the molten metal in the mould cavity. The mould cavity is properly filled with molten metal and bubbles are pushed out of the mould cavity by centrifugal force. At the gating from behind, only two samples have small percentage of porosity. At the gating from the left, the porosity forms only at $400 \mathrm{rpm}$. From the obtained results, we can be conclude, that the high mould rotations per minute are the best for avoiding the porosity formation in centrifugally cast castings. When the cross sections are compared, it is obvious that the cross section A contains the highest percentage of porosity. This cross section is affected by the centrifugal and by Coriolis forces. The result of this is the movement of gas bubbles not only in the direction to the axis of the mould rotation by centrifugal forces, but also to the direction of the mould rotation by Coriolis force.

At most of the samples, the higher percentage of porosity is formed in the left side of the observed area. But at low mould rotations per minute, especially at the direct gating and gating from the right, the porosity is distributed almost equally on the left and right sides. This is influenced mainly by low centrifugal force, which does not affect the formed gas bubbles at such force as at the high mould rotations per minute. It is established that at the gating from the right, the porosity distribution is more uniform. This is the result of the clockwise rotation of mould, when, at filling the mould cavity from the right, the force from the molten metal flow acts against the Coriolis force.

It can be generally stated that porosity in castings formes mainly at the low mould rotations per minute. The worst from the porosity point of view is the direct gating.

The results proved that the gas bubbles in the molten metal are pushed in the direction of the rotation axis by centrifugal force and in the direction of rotation by the Coriolis force during filling the mould.

\section{CONCLUSION}

The influence of revolutions per minute and the direction of gating on porosity is studied on the centrifugally cast samples of $\mathrm{ZnAl} 4 \mathrm{Cu} 3$ zinc alloy. It is determined that the highest revolutions per minute of the mould eliminate porosity inside the casting. It is also determined that, at higher revolutions per minute of the mould, the gating type has no significant influence on planar distribution of porosity.

The experiments proved that the centrifugal and Coriolis forces affect the final distribution of porosity so that in the area from the axis of rotation to the centre of casting (left side of the observed area) percentage of porosity is higher.

\section{Acknowledgements}

The paper is a part of the KEGA Project No. 007STU-4/2018 Multimediálna podpora výučby technológie zlievarenstva a jej obsahová optimalizácia v rámci krajín V4. (Multimedia tools for teaching foundry technology and its content optimization in the countries of the Visegrad group.)

\section{References:}

1. CLARSON, K. D. and all. 2002. Modeling of porosity formation and feeding flow in steel casting. Chicago: Steel Founders'Society of America. 
2. TIAN, C. and all. 2002. Effect of melt cleanliness on the formation of porosity defects in automotive aluminium high pressure die castings. Journal of Materials Processing Technology, 122(1), pp. 8293.

3. SHIPING, W. and all. 2003. Numerical simulation of off-centered porosity formation of TiAl-based alloy exhaust valve during vertical centrifugal casting. Modelling and simulation in materials science and engineering, 11, pp. 599-608. 